\title{
O Cluster cinematográfico de paUlínia: UMA ANÁLISE DA INOVAÇÃO E DO EMPREENDEDORISMO DA INDÚSTRIA DO CINEMA EM PAULÍNIA-SP'
}

\author{
THE CINEMATOGRAPHIC CLUSTER OF PAULÍNIA: AN ANALYSIS OF INNOVATION AND \\ ENTREPRENEURSHIP IN PAULÍNIA-SP MOVIE INDUSTRY
}

\author{
Recebido em 21.01.2013. Aprovado em 10.09.2013 \\ Avaliado pelo sistema double blind review \\ DOI:http://dx.doi.org/10.12712/rpca.v7i3.254
}

\begin{abstract}
Gustavo Mota Uchoa
akggustavo@gmail.com

Centro de Ciências Sociais e Aplicadas da Universidade Presbiteriana Mackenzie (CCSA/ UPM) - São Paulo SP - Brasil.
\end{abstract}

\section{Reinaldo Dias}

reinaldias@hotmail.com

Centro de Ciências Sociais e Aplicadas da Universidade Presbiteriana Mackenzie (CCSA/ UPM) - São Paulo SP - Brasil.

\section{Resumo}

Este artigo tem por objetivo caracterizar a estruturação produtiva da indústria cinematográfica de Paulínia-SP, observando como as empresas e o Estado se relacionam no polo cinematográfico lá instalado, tendo em vista os conceitos de Cluster, especialização flexível e competitividade; além de levar em consideração a história da produção de cinema no país, desde seu surgimento no século XIX, passando pelas tentativas de industrialização, pela criação da estatal Embrafilme e estabelecendo o cenário conjuntural da "retomada" na década de 90 e começo do século XXI. Após a construção desse cenário, buscaremos avaliar as perspectivas de competitividade do cinema brasileiro, desde muito cedo "sufocado" pelo filme estrangeiro e com problemas endêmicos de dependência do Estado. Buscamos identificar se há um arranjo produtivo local em torno dessa atividade e seu estado de desenvolvimento, ressaltando sua relevância para o futuro do cinema no Brasil.

Palavras-chave: Cinema brasileiro. Competitividade. Cluster. Especialização flexível.

\begin{abstract}
This paper's objective is to find out how is the movie industry in Paulínia-SP arrayed, observing how the companies and the public sector interact, under the lights of concepts such as Cluster theory, flexible specialization and competitivity, and also taking into account historical aspects of the country's cinematographic production; from its very beginning, through the attempts of establishing a movie industry, the creation of the state enterprise Embrafilme and finally building a contextual scenario of the "retomada" in the 90's and early 00's. With the construction of this scenario, we intend to evaluate the perspectives of competitivity for the Brazilian cinema, "suffocated" by the foreign films since the 30's and stuck with endemic problems such as Government dependency. We sought to find out if there is indeed a Movie Cluster there and its stage of development, also considering the weight of such findings for the historic moment and what it represents for the future of Brazilian cinema.
\end{abstract}

Keywords: Brazilian cinema. Cluster. Competitivity. Flexible specialization.

\footnotetext{
${ }^{1}$ Este artigo é resultado de pesquisa realizada no âmbito do Programa de Iniciação Científica do Centro de Ciências Sociais e Aplicadas da Universidade Presbiteriana Mackenzie (UPM).
} 


\section{Introdução}

Não é recente a discussão sobre o futuro do cinema brasileiro. Desde que o cinema foi percebido como arte, são discutidos temas como a importância cultural do cinema, as condições de sua produção e financiamento e a estética "brasileira" desse cinema. Também, em vários momentos, se discutiu o posicionamento do Estado e do setor privado na perpetuação desse cinema, da criação de leis de incentivo e de políticas culturais à fundação de uma empresa estatal para financiamento e distribuição de filmes. No entanto, o cinema brasileiro parece nunca ter verdadeiramente decolado, nem mesmo adquirido a importância a que almejava dentro de seu próprio berço.

Questiona-se então onde estão os gargalos dessa cadeia de valor? O que falta mudar para que o cinema brasileiro seja verdadeiramente competitivo, para que ele ocupe o seu espaço, para que seja reconhecido?

Neste artigo, discutiremos a respeito do Polo cinematográfico de Paulínia, sobre competitividade e sobre estruturação produtiva, visando identificar possibilidades de desenvolvimento para o cinema nacional e também os fatores que criaram essas condições de competitividade, abordando também o papel do Estado nessa relação.

\section{Clusters e Competitividade}

A Prosperidade de uma nação ou região não é herdada, nem tampouco depende unicamente das características naturais ali presentes ou da disponibilidade de mão de obra. A prosperidade não é fruto da taxa de juros ou do valor da moeda, fatores há muito tempo considerados determinantes para o sucesso econômico de um país, dentro do paradigma das teorias econômicas tradicionais. A prosperidade de uma nação é consequência da vantagem competitiva dessa nação, e essa competitividade depende da capacidade da indústria local de inovar e se aprimorar. (PORTER, 1990a)

Para se identificar um país ou região competitivos, portanto, não se usam os mecanismos do velho paradigma como levantamento de indicadores macroeconômicos ou de vantagens comparativas (recursos naturais, mão de obra abundante, clima, etc.). Já de início esse tipo de análise nos leva a contradições como o caso do Japão (cuja moeda é desvalorizada e a indústria muito competitiva) e da Suíça (onde há poucos recursos naturais e a mão de obra é cara, mas o país é próspero e possui setores competitivos). O único conceito que se mostra adequado para medir a competitividade de uma nação é produtividade e, por extensão, a capacidade de um país ou região de crescer economicamente e, com isso, aumentar o padrão de vida de seus membros. (PORTER, 1990a)

Competidores mais ágeis inevitavelmente tomarão o lugar de uma indústria que permanece a mesma com o passar do tempo. Os chineses alcançaram o nível tecnológico dos japoneses e sul coreanos na produção de eletrônicos da mesma forma que nos anos 80 os japoneses e sul coreanos ultrapassaram os estadunidenses e alemães na indústria automobilística. Nem mesmo as trincheiras mais resistentes, construídas sobre economias de escala, tecnologias revolucionárias ou protecionismo podem fazer frente ao dinamismo dos novos entrantes. É sempre uma questão de tempo para aqueles que estão parados serem derrubados por concorrentes mais flexíveis. Essa competição implica num cenário no qual uma vantagem adquirida tem que ser substituída por outra enquanto a empresa ainda usufrui dos benefícios dela. (PORTER, 1990a)

Se, para o começo do século XX a competitividade significava produção em massa, economias de escala e indústrias gargantuanas sob a égide de Henry Ford e se a sociedade um dia abraçou essa realidade de "Tempos modernos" (de Chaplin), "Imbecis especializados" (DE MASI, 2000) e do Moloch de Fritz Lang como imortal, o começo do século XXI já contempla esse modelo industrial numa fase de extrema decadência. (PIORE e SABEL, 1984, p.21-26). O sistema de produção em massa era eficiente por poder transformar mão de obra desqualificada e outros insumos em produtos padronizados e de baixíssimo custo através da divisão funcional de tarefas (que agilizava a especialização do trabalhador e minimizava o tempo de produção total) e da mecanização do processo 


\section{O CLUSTER CINEMATOGRÁfiCo de PAULÍNIA: UMA ANÁLISE DA INOVAÇÃO E dO EMPREENDEDORISMO DA INDÚSTRIA DO CINEMA EM PAULÍNIA-SP}

(uma vez decompostas as tarefas de um artesão em unidades menores de movimentos, era possível desenhar uma máquina pra desempenhar tal função de forma mais rápida e precisa que um operário) (PIORE E SABEL, 1984. p. 44-48), contudo, não se adaptou aos choques de aumento de custo da mão de obra e de insumos essenciais como derivados de petróleo (PIORE E SABEL, 1984. p. 175-181). Da mesma forma, o modelo de produção em massa era extremamente dependente da quantidade e da uniformidade da demanda e começou a entrar em colapso com a entrada de novos concorrentes, crescente saturação dos mercados e diversificação dessa demanda (PIORE E SABEL, 1984. p. 184192) devido a sua inflexibilidade (as empresas desse modelo eram incapazes de deslocar seus recursos para alterar suas atividades com agilidade) (PIORE E SABEL, 1984. p. 21-23). Piore e Sabel consideram como uma das possíveis saídas para a crise da produção em massa um modelo de estruturação produtiva chamado "Especialização produtiva", através do qual empresas poderiam realocar mais facilmente seus recursos e operarem com séries de produção menores sem sofrerem com os custos proibitivos que isso implicaria no paradigma da produção em massa (PIORE E SABEL, 1984. p. 265-268). A especialização produtiva pressupõe a fragmentação da cadeia de valor (antes concentrada nas indústrias de produção em massa), ou seja, onde havia uma única fábrica no modelo fordista, passa-se a encontrar várias empresas de porte menor, que cuidam de cada etapa da cadeia de valor, na qual são especialistas.

Se Piore e Sabel não demonstravam certeza a respeito da especialização flexível e não conseguiam determinar um modelo específico que as pequenas organizações adotariam para competirem no futuro, essa questão é resolvida por Porter (1990a) que conduziu um estudo em 10 países para identificar fatores que trazem competitividade às nações. Por que certas companhias sediadas em determinadas regiões têm capacidade maior pra constante inovação e aprimoramento? Por que elas conseguem, de maneira implacável, atravessar os obstáculos que acompanham a mudança e o desenvolvimento? Porter responde a esses questionamentos discriminando os 4 fatores que compõem o "Diamante da vantagem competitiva" (que viria a ser conhecido como "Diamante de Porter")(PORTER, 1990a; PORTER, 1990b):

Condição de fatores: corresponde a vantagens comparativas do país ou região, ou seja, sua condição em termos de infraestrutura, trabalho especializado e recursos naturais. As teorias clássicas de comércio internacional giram em torno desse aspecto, ditando que um país que fosse intensivo em um determinado fator deveria dedicar-se à produção e exportação desse fator ou mesmo ainda essa produção seria determinada pela facilidade de produzir algo em um país em relação a produzir o mesmo em outro (GONÇALVES, BAUMANN, CANUTO e PRADO, 1998. p.3-35).

Porter (1990b, p. 90) afirma que o papel desses fatores é muito mais complexo do que se supunha, já que os fatores mais importantes para o desenvolvimento da maioria das indústrias são criados dentro do país e não simplesmente se encontram lá naturalmente. Assim, o 'estoque' de fatores em qualquer momento é muito menos importante do que a capacidade e a velocidade com a qual se os cria.

Esses fatores podem ser divididos em (PORTER, 1990b, p. 91-92):

- Recursos humanos (quantidade, capacidade e custos do pessoal)

- Recursos físicos (abundância, qualidade, acessibilidade e custo dos recursos naturais, clima, tamanho da região, proximidade de outras regiões fornecedoras e proximidade de outras regiões de mercado)

- Recursos de conhecimentos (o "estoque" que um país tem de material científico e técnico, além de dados de mercado, estocado em diversos locais, desde bases de dados até universidades e centros de pesquisa)

- Recursos de capital (quantidade e custo do capital disponível para o financiamento das operações da indústria) 


\section{Gustavo Mota Uchoa e Reinaldo Dias}

- Infraestrutura (sistema de transporte, sistema de comunicação, rede elétrica etc.)

Esses fatores, quando presentes, e somadas a condições superiores de custo e qualidade, aumentam a competitividade da indústria (PORTER, 1990b, p.92). Essa competitividade, no entanto, está condicionada à efetividade com que são distribuídos, ou seja, reforça-se a ideia de que a simples disponibilidade desses fatores não é suficiente para que a região ou a indústria se tornem competitivas.

Condições de demanda: corresponde à maneira como a demanda interna do país se porta em relação a um determinado setor produtor de bens ou serviços. Porter (1990b, p.103) discrimina 3 atributos gerais dessas condições que são significativos:

-Composição da demanda: a composição da demanda é o que determina como a empresa percebe, interpreta e reage às necessidades dos consumidores. Esse fator traz vantagem competitiva ao dar às empresas locais uma ideia de seu quadro geral de necessidades antecipadamente, e também, se esses consumidores forem exigentes, forçam as empresas a inovarem e desenvolverem competências que as fortalecerão para a competição no mercado externo (PORTER, 1990b. p.103-110).

-Tamanho e padrão de crescimento do mercado: esse aspecto serve para reforçar as vantagens obtidas pelas demais dimensões que caracterizam as condições de demanda, também podendo facilitar o desenvolvimento de indústrias que aproveitam economias de escala. Por último, a rapidez do crescimento interno da demanda de um país ou região pode levar a uma taxa mais acelerada de inovação, pois diminui o receio das organizações de que seus investimentos serão redundantes, desnecessários ou infrutíferos (já que um mercado aquecido aumenta as chances de retorno desse investimento) (PORTER, 1990b. p.110-115).

-Capacidade de internacionalização da demanda interna: quando parte da demanda é composta por empresas multinacionais, estrangeiros no país ou pessoas que viajam muito, aumentam-se as chances do produto ser bem recebido no exterior, pois se aprimoram as noções que as organizações da região têm a respeito das necessidades e particularidades daquele grupo de consumidores. (PORTER, 1990b. p.115-117)

Indústrias correlatas e de apoio: A presença de indústrias correlatas e de apoio internacionalmente competitivas reforça a vantagem de um setor. Os fornecedores provêm melhor acesso (mais rápido e a menor custo) a insumos de alta qualidade, como ocorre, por exemplo, na indústria calçadista de Franca-SP, onde estão concentradas empresas da cadeia produtiva desde a produção do couro até a comercialização internacional dos calçados (SONZOGNO, 2003; GARCIA, 2002 apud SONZOGNO, 2003; SUZIGAN ET. AL., 2001 apud SONZOGNO, 2003). Além disso, a intensa relação de trabalho entre essas empresas e seus clientes propicia alto grau de inovação e aprimoramento, trazendo vantagens competitivas para ambas as partes através da constante discussão das necessidades de seus clientes e de fluxos de informação e tecnologia, o que resulta em externalidades positivas para todos os envolvidos e, em última instância, vantagem competitiva. (PORTER, 1990b. p.118-123)

Indústrias correlatas são organizações que possuem atividades iguais ou semelhantes na cadeia de valores, como, por exemplo, ocorre no cluster do setor têxtil em Valença-RJ, no qual estão presentes facções, confecções e lavanderias voltadas para o desenho, a produção, ao tratamento e à comercialização de tecidos jeans (COUTINHO, 2008). A presença de indústrias correlatas competitivas num país ou região traz vantagens como a possibilidade de intercâmbios técnicos, a possibilidade de que novas oportunidades na atividade sejam percebidas e ajuda a puxar a demanda local por produtos e serviços complementares, além de certos profissionais especializados. (PORTER, 1990b. p.123-126)

Estratégia, estrutura e rivalidade: A própria razão de ser da administração é a de obter maior efetividade da organização através da gestão das atividades e controle dos recursos. De certa forma, é óbvio que melhores práticas administrativas trazem melhores resultados, mas é importante ressaltar que não há modelos universais e que cada prática se adequa à cultura de uma região de forma distinta de outra. Aplicar um modelo de gestão que apresentou sucesso em outras regiões pode ser catastrófico 


\section{O CLUSTER CINEMATOGRÁfiCo de PAULÍNIA: UMA ANÁLISE DA INOVAÇÃO E dO EMPREENDEDORISMO DA INDÚSTRIA DO CINEMA EM PAULÍNIA-SP}

para uma organização. (PORTER, 1990b p. 126-142; PORTER, 1990a)

A dimensão da rivalidade corresponde a visão do ambiente competitivo com um local de evolução agressivamente darwinista. Um mercado no qual os mais fortes sobrevivem e que está repleto deles, sem nenhuma barreira que os impeça de competirem entre si gerará empresas mais competitivas e aprimoradas, mais aptas a competir no mercado internacional do que aquelas que não precisaram inovara pra sobreviver e que cresceram dependentes da sua reserva de mercado e outras proteções governamentais ou de oligopólio. (PORTER, 1990a)

Cluster: O Cluster ou Arranjo produtivo local (APL) é uma forma de estruturação produtiva caracterizada pela aglomeração de MPMEs (micro, pequena e média empresas) ligadas a um mesmo setor de atividades e concentradas num mesmo território (CASSIOLATO e LASTRES, 2003; SEBRAE, 2002; SEBRAE, 2010; PORTER, 1990b).

Enxergando esse arranjo sob a perspectiva dos conceitos de vantagem competitiva e de especialização flexível, percebemos um modelo de produção mais flexível do que o encontrado no paradigma das grandes empresas e também um modelo que permite às empresas presentes na região do Cluster se organizarem de forma a obter vantagem competitiva, aproveitando cada elemento descrito no diamante de Porter.

-Da perspectiva da condição de fatores: O APL tende a se formar em regiões nas quais há vantagens comparativas em quantidade e qualidade aceitáveis para o desenvolvimento das empresas da atividade central (mesmo que relativamente), a partir desse ponto, a aglomeração das indústrias provocará um efeito multiplicador do potencial desses recursos, desde que o Cluster venha a se desenvolver.

-Da perspectiva da Natureza da demanda: O APL se desenvolverá mais intensamente se puder suprir mercados relativamente próximos e cujas características da demanda o incentivem a inovar e aprimorar constantemente.

-Da perspectiva das indústrias correlatas e de suporte: a concentração geográfica de empresas relacionadas a uma determinada atividade rapidamente atrairá indústrias fornecedoras e correlatas (se sua vinda não for previamente planejada), em busca de facilidades de custo e outros benefícios relacionados à proximidade.

-Da perspectiva da rivalidade no mercado: a presença de várias organizações do mesmo setor acirrará a competição interna, forçando essas empresas a inovar constantemente e aprimorar seus processos de produção, sem prejuízo da possibilidade de cooperação entre rivais em elementos do processo que não envolvam a atividade central (por exemplo, reduzindo custos ao dividirem espaço num contêiner).

Em suma, Clusters são concentrações geográficas de empresas e instituições interdependentes, englobando redes de produtores e entidades importantes para a competição (tais como faculdades especializadas, indústrias de base relacionadas, indústrias correlatas, órgãos de financiamento governamentais, etc.) (Porter, 1998), permitindo que empresas de portes menores tenham acesso a vantagens típicas das maiores como "gravitação de recursos" (capacidade de atrair fornecedores, mão de obra e financiamentos especiais) e pesquisa e desenvolvimento (através de iniciativas coletivas).

É possível classificar os Arranjos produtivos locais (Clusters) dividindo-os de acordo com seu grau de desenvolvimento.

Para Amorim (1998, apud BARROSO e BATISTA, 2003), um Cluster em estágio incipiente de desenvolvimento é chamado de Pré-Cluster e se caracteriza pela mera presença de indústrias independentes de um mesmo setor na área observada; um Cluster no qual as empresas começam a se relacionar e se concentrarem em maior quantidade no local é denominado Cluster Emergente; Quando as empresas intensificam suas ligações e passam a se relacionar com outras instituições, identificamse Clusters em expansão; e quando as indústrias se relacionam intensamente entre si e com outras instituições, caracteriza-se um Cluster independente. Já para o SEBRAE (2010), a divisão se dá em 
três níveis:

Incipientes: São desarticulados e se caracterizam pela ausência ou presença frágil de relações interempresariais não há instituições de apoio como faculdades e centros de treinamento de mão de obra voltados para a atividade do arranjo, também não há estrutura de cooperação ou governança. Esse tipo de arranjo apresenta baixo desempenho empresarial, foco individual e ausência de interação com o poder público. Seu mercado é mais local. (SEBRAE, 2010)

Em desenvolvimento: Já são relevantes para o desenvolvimento local e incentivam o empreendedorismo interno e externo na região, surge uma preocupação com a cadeia produtiva e as empresas passam a se organizar em entidades de classe. Apresentam foco setorial e já há interação com órgãos de classe para a defesa de interesses regionais. Nesse ponto, as empresas do arranjo já são produtivas e sua presença atrai empreendedores para a cadeia produtiva, contudo, ainda se identificam gargalos nessa cadeia e as empresas do Cluster têm dificuldade de se relacionar com o setor público e de acesso a serviços especializados. Seu mercado varia de local a nacional. (SEBRAE, 2010)

Desenvolvidos: São Clusters cuja articulação é consistente, resultando em interação, cooperação e aprendizagem, possibilitando inovações de produtos e processos e gerando maior competitividade (SEBRAE, 2010) e, logo, aumentando a capacidade da região de crescer economicamente aumentando o padrão de vida de seus habitantes (PORTER, 1990a). O foco desse tipo de arranjo é territorial, aqui já existem relações desenvolvidas entre órgãos representativos do setor e as entidades públicas, universidades, indústrias correlatas, instituições financeiras e organizações do terceiro setor. As empresas num cluster desenvolvido se não o são, tendem a se tornar competitivas internacionalmente (SEBRAE, 2010; Porter, 1998).

Através do uso desses conceitos, procuraremos analisar e descrever a situação do polo cinematográfico de Paulínia, identificando se houve a formação de um Cluster de entretenimento (cinema, notavelmente) na cidade e em que estágio de desenvolvimento esse arranjo se encontra. Após esse trabalho, nos dedicaremos a analisar as perspectivas de competitividade do cinema nacional para o futuro tendo em vista um panorama histórico da indústria cinematográfica brasileira.

\section{Um panorama histórico da produção cinematográfica no Brasil:}

A história do Cinema no Brasil começa no final do século XIX com a chegada do cinematógrafo, trazido da Europa por imigrantes. Em 1898, Afonso Segreto registrou imagens da baía de Guanabara a bordo do Brésil. No entanto, a produção e a exibição de filmes nesse primeiro momento foram parcas e inconstantes até que, em 1907, a distribuição de energia elétrica no Rio de janeiro fosse devidamente regularizada. Ainda nesse mesmo ano foram instaladas mais de 20 salas de exibição na Avenida Central (GONÇALVES, 2009, p. 35-46; MinC, s/d; SIMIS, 1996, p. 67-75).

O cinema brasileiro da "bela época" se caracterizava pelo binômio produtor-exibidor, ou seja, os filmes produzidos aqui nos primeiros anos do século XX eram feitos por donos de salas de exibição ou seus associados, garantindo que haveria a oportunidade de exibir a película (um sistema no qual ainda havia concentração da cadeia produtiva entre a produção, a distribuição e a exibição numa única organização ou pessoa). (GONÇALVES, 2009, p. 35-46; SIMIS, 1996, p. 67-75; GOMES, 1980 apud SIMIS, 1996).

Ao final da primeira década, deu-se início a uma invasão de produções internacionais, já organizadas em modelos de produção mais avançados e cujos filmes tinham conteúdo mais elaborado, dessa forma, também o Brasil sofreu uma transformação, conforme os donos de salas de exibição se organizavam para atender às necessidades de escoamento dos filmes estrangeiros, principalmente estadunidenses. Consequência dessa "invasão" foi também a adoção dos padrões de produção norteamericanos como paradigma para a realização de filmes no Brasil. (GONÇALVES, 2009, p. 35-75; QUEIROZ, 1981 apud SIMIS, 1996)

Em oposição a esse paradigma, alguns produtores locais procuraram se utilizar de outros subterfúgios 


\section{O CLUSTER CINEMATOGRÁfiCo de PAULÍNIA: UMA ANÁLISE DA INOVAÇÃo E dO EMPREENDEDORISMO DA INDÚSTRIA DO CINEMA EM PAULÍNIA-SP}

para permanecerem ativos, como a obtenção de patrocínio da burguesia urbana (em troca da promoção pessoal e/ou dos negócios do indivíduo) e a exploração de temáticas que o cinema internacional não abrangia como as paisagens locais e a vida cotidiana da população local (GONÇALVES, 2009, p. 3575; SIMIS, 1996).

Ainda dentro do contexto da república velha, pode-se notar que as produções, em geral, abordam temáticas nacionalistas, seja adaptando clássicos da literatura, seja tratando dos costumes e do cotidiano, fruto da visão do cinema como um projeto de formação de uma identidade nacional (com raízes ainda no século XIX) e do desejo de uma classe social de produtores imigrantes de se integrarem na sociedade da qual agora faziam parte e ascenderem dentro dela (GONÇALVES, 2009, p. 35-75; SIMIS, 1996).

Nas décadas de 10 e 20, proliferaram alguns ciclos de produção cinematográfica no Brasil fora do eixo Rio-São Paulo (em Barbacena, Pouso Alegre e pelotas, por exemplo). Esses surtos de produção cinematográfica conseguiram, com maior ou menor sucesso, realizar produções cinematográficas até serem dissolvidos, em geral por serem incapazes de concorrer com a fita estrangeira (GONÇALVES, 2009, p. 67-75).

Alguns desses ciclos, no entanto, foram bastante resistentes como o de Recife e o de Cataguases. O ciclo de Recife envolveu a participação de mais de 300 pessoas e a formação de produtoras locais como a Aurora, mas os problemas infraestruturais eram muitos e, aliados à instabilidade econômica e à incapacidade das produções recifenses de se pagarem, levaram ao fim desse ciclo (GONÇALVES, 2009, p. 69-70; LOBATO e RAMOS, 1987 apud GONÇALVES, 2009, p. 69-70; ARAÚJO, 2008). Já o de Cataguases teve como figura principal o cineasta Humberto Mauro, cujas produções Thesouro perdido (1927), Brasa dormida (1928) e Sangue Mineiro (1929), são clássicos imortais do cinema brasileiro. Esse ciclo sofreu o mesmo destino de todos os outros, encerrando o capítulo da história da produção cinematográfica brasileira no contexto da república velha (GONÇALVES, 2009, p. 71-75; RAMOS E MIRANDA, 2000).

Foi durante o Estado novo que a produção cinematográfica brasileira tentou pela primeira vez moldarse de forma industrial (até então, buscava-se um padrão técnico e de fluidez narrativa semelhante ao da produção hollywoodiana, mas não havia produtoras com características industriais no Brasil), era uma cultura que tentava sair de um patamar que se entendia como atrasado (FERREIRA, 2006). As Companhias centrais nessa conjuntura foram a Cinédia de Adhemar Gonzaga (1930), a Brasil Vita Filmes de Carmem Santos (1934) e a Atlântida de Arnaldo de Faria e seus associados. (GONÇALVES, 2009, p. 108).

Com apoio da revista Cinearte, a Produções Cinédia foi fundada por Adhemar Gonzaga em 1930. Era bem-equipada, almejando a qualidade dos estúdios de Hollywood (LYRA, 2007) e já em novembro daquele ano produziu Lábios sem Beijos. Com a construção da Cinédia, Gonzaga visava por em prática seu projeto estético-cultural para o cinema brasileiro, orientado por um ideal de modernidade, nacionalismo e desenvolvimento, mas também com os elementos industriais do modelo norteamericano (FERREIRA, 2006). Em 1936, o estúdio tinha a capacidade de filmar três produções simultâneas e, em 1937, foi considerada pelo Jornal do Brasil, como detentora do maior parque industrial cinematográfico de toda a América do Sul (ASSAF, 1987 apud GONÇALVES, 2009, p.110).

No entanto, mesmo com toda essa estrutura e com apoio do governo, a Cinédia teve que paralisar suas atividades pela primeira vez em 1941 devido à escassez de matéria prima, decorrente da segunda guerra mundial e problemas de pagamento (GONÇALVES, 2009, p.111). Ainda assim, continuou suas atividades, enfrentando diversas crises e produzindo filmes importantes para a história do cinema brasileiro. A Empresa continua em operação. (CINÉDIA, s/d) 
A Brasil Vita filmes entra para a história mais em função de suas realizações cinematográficas individuais do que por sua estrutura produtiva, dentre as produções mais relevantes podemos destacar Argila, de 1940; e Inconfidência mineira, de 1948. (IMDb, s/d)

A Atlântida, fundada em 1941 (LYRA, 2007), é conhecida pela produção de “chanchadas”, que são filmes com argumentos simples e números musicais homogêneos, sendo então filmes de apelo popular e de baixa qualidade de produção, considerados inferiores pelos então formadores de opinião na área de cultura, mas consumido pela população (CATANI, 2004; LIMA, 2007; LYRA, 2007). Em 1947, O exibidor e distribuidor Luís Severiano Ribeiro se torna sócio da Atlântida, trazendo à produtora uma grande vantagem competitiva em termos de canais de distribuição nacional (GONÇALVES, 2009, p.156; VIEIRA e RAMOS, 1987 apud MENDONÇA, 2007), no entanto a evolução da qualidade dos filmes só viria frente à concorrência da Cia Cinematográfica Vera Cruz (mesmo que tenha sobrevivido por mais tempo) e da televisão (SALLES, s/d; ). A Atlântida produziu seu último filme em 1962 (IMDB, s/d, LIMA, 2007).

Na transição da década de 40 para a de 50, A cidade de São Paulo era palco de uma renovação do aparato cultural, resultado de uma situação de ascensão econômica, que posicionava a cidade como polo industrial e centro econômico nacional e também sentia os impactos iniciais da mercantilização cultural e da massificação dos meios de comunicação. (MARTINELLI, 2002 apud GONÇALVES, 2009, p.164; GONÇALVES, 2009, p.164-165; ORTIZ, 2001 apud LIMA, 2007). Nesse contexto, percebia-se o surgimento de uma burguesia industrial, em grande parte imigrante da Europa, que não encontrava uma manifestação cultural que a representasse e era desejoso de se integrar com a cultura local (GONÇALVES, 2009, p.164-165; BERNARDET, 1979 apud LIMA, 2007). Dentro dessa conjuntura, é fundada em 1949 a Companhia cinematográfica Vera Cruz, a partir dos investimentos dos empreendedores imigrantes Franco Zampari e Francisco Matarazzo Sobrinho, com objetivo de transformar o cinema brasileiro em um produto cosmopolita e urbano, característica que refletia as transformações pelas quais passava a cidade de São Paulo nesse período de crescente industrialização. Esse empreendimento visava trazer à produção cinematográfica brasileira uma qualidade técnica e um conteúdo artístico que até então não possuíra e também moldar tal produção conforme o ideal dessa burguesia industrial que ascendia (GONÇALVES, 2009, p.164-170; LIMA, 2007).

Um dos fatores que contribuíram para a qualidade das produções da Cia Vera cruz foi a fundação, um ano antes, do Teatro brasileiro de comédia (TBC), que compartilhava com a companhia cinematográfica o grupo fundador, a estrutura administrativa e profissionais de diversas áreas, como atores, diretores e técnicos (GONÇALVES, 2009, p.166-167; RAMOS e MIRANDA, 2000. p. 561562) (aqui podemos até nos arriscar a dizer que a Cia Vera Cruz contava com uma empresa correlata e com vantagens comparativas em termos de mão de obra especializada, embora utilize esses fatores sem fragmentar a cadeia de valor). Segundo Gonçalves (2009, p.167):

A excelência da qualidade das produções do TBC e a discrepância que se estabelecia entre estas e o que tinha sido produzido até então no cenário teatral brasileiro faziam com que se pudesse considerar o TBC como um ponto de virada do teatro nacional (...) à semelhança do teatro da Major Diogo [TBC], a Vera Cruz também se organizava de modo empresarial, com equipes fixas de funcionários, excelência de produção e rigor no padrão de qualidade. Além disso, é do TBC que saem vários dos artistas e técnicos que vão trabalhar nos novos estúdios de cinema...

A estética de produção dos filmes da Vera Cruz, apesar de seu modo de produção industrial, era mais similar à das produções europeias do que à das produções de Hollywood (o que é relevante para esse estudo somente quanto ao direcionamento de público que essa característica representa, a qual visava conquistar o público brasileiro para o cinema e à realização de "filmes de valor", em vez de seguir o modelo de "estandardização" estadunidense) (GONÇALVES, 2009, p.169-170) e, de qualquer forma, também nunca conseguiu atingir o padrão de racionalização da produção que esse modelo 


\section{O CLUSTER CINEMATOGRÁfiCo de PAULÍNIA: UMA ANÁLISE DA INOVAÇÃO E dO EMPREENDEDORISMO DA INDÚSTRIA DO CINEMA EM PAULÍNIA-SP}

representava.

Durante seus cinco anos e poucos meses de existência, a Vera Cruz produziu 18 filmes longametragem, sendo que títulos importantes como $O$ cangaceiro de Lima Barreto (1953) chegaram até a impactar o mercado internacional (o filme foi premiado como melhor filme de aventuras no festival de Cannes em 1953 e, na França até gerou uma moda de se usar sandálias femininas que imitavam as alpercatas nordestinas) (GONÇALVES, 2009, p.170-173; MARTINELLI, 2002 apud GONÇALVES, 2009, p.173).

A Vera Cruz representou um grande avanço em termos de aprimoramento técnico e formação de profissionais qualificados na área. "A existência da Vera Cruz se desdobrou no surgimento de outras produtoras cinematográficas (...) surgidas com o intuito de evitar os desacertos da Vera Cruz ou de copiar-lhe os acertos" (GONÇALVES, 2009, p.189-190). A Vera cruz entrou em decadência a partir de 1953 em função do desconhecimento do mercado nacional e internacional, da ausência de um planejamento adequado para o "fator negócio" do empreendimento e dificuldades decorrentes da terceirização da distribuição de seus filmes (confiada à Columbia), dessa forma, o baixo retorno dos investimentos e seu crescente endividamento levaram a companhia a entregar a administração dos estúdios de São Bernardo do Campo ao Banco do Estado (RAMOS e MIRANDA, 2000. p. 561-562; LIMA, 2007).

A Vera Cruz é vista como um bastião da tentativa do cinema brasileiro em adquirir qualidade técnica e eliminar os gargalos políticos e econômicos que impediam a proliferação do cinema no Brasil e do "resgate do cinema brasileiro" e mesmo ela não obteve sucesso, por não compreender como as dimensões estética-artística e econômica-técnica se relacionavam. (FABRIS, 1994 apud MENDONÇA, 2007).

Havia uma dicotomia entre produção e distribuição/exibição e esse era (e é) um dos principais causadores da "profunda fraqueza" do cinema brasileiro, ou seja, os distribuidores e produtores nacionais não formavam alianças mercantis e não havia tampouco uma organização que englobasse essas áreas verticalmente, então o distribuidor/exibidor preferia manter-se num nicho relativamente seguro (negociando filmes estrangeiros) a firmar parcerias com produtores locais que, por sua vez, realizavam seus filmes sem garantia de que trariam retorno financeiro (MENDONÇA, 2007). A permanência desse tipo de problema ao longo do século $\mathrm{XX}$, somada ao fato de que a produção bruta de filmes brasileiros era relativamente pequena, levou também há uma complicação indireta: o condicionamento do público brasileiro a um modelo dominante de estética, provocando uma nova diminuição do espaço de exibição dos filmes nacionais no longo prazo (MENDONÇA, 2007).

\section{História recente do cinema brasileiro}

A Embrafilme foi a maior companhia distribuidora do cinema brasileiro. Foi também a principal financiadora, e co-produtora de filmes nacionais durante seu período de existência (1969 -1990) (GATTI, 2007a; AMANCIO, 2000 apud IKEDA, 2010; MARSON, 2006). Ela foi criada em 1969 através do decreto 862/69 E tinha como uma de suas missões trazer o desenvolvimento para a indústria cinematográfica nacional, trazendo uma solução para o grande problema de escoamento da produção. (GATTI, 2007a; BRASIL, 1969)

Esse cenário deflagra um envolvimento do Estado numa questão de indústria e cultura, buscando dar novos rumos ao cinema brasileiro e fortalecer sua competitividade, tanto no mercado nacional como no internacional (nesse momento, não discutiremos se cabe ao Estado esse papel de empreendedor, tampouco levaremos em consideração os desdobramentos político-ideológicos da criação da Embrafilme que não tiverem relações de causa e efeito facilmente identificáveis com a produtividade do cinema brasileiro e outros aspectos econômicos diretamente relacionados).

Até 1973, a Embrafilme e outros órgãos que se relacionavam com a produção cinematográfica se 


\section{Gustavo Mota Uchoa e Reinaldo Dias}

encontravam num período de adaptação administrativa, definindo funções, espaços de influência e prioridades de ação (seguindo os objetivos definidos em seu decreto de criação). Em 1973, o INC (instituto nacional de cinema) se funde à Embrafilme e o então diretor Walter Graciosa inicia um processo de reestruturação administrativa e técnica, para que a empresa pudesse, de fato, ser capaz de executar as tarefas a que se propunha (GATTI, 2007a).

Entre 1974 e 1978, houve nova reformulação da Embrafilme para lidar com problemas de inadimplência dos financiamentos por parte dos produtores e a implantação do Concine (Conselho nacional de cinema), que tinha por função regular e fiscalizar, além de formular políticas de preços e observar o cumprimento das cotas de obrigatoriedade de exibição de filmes nacionais instituída pelo governo militar (GATTI, 2007a; MARSON, 2006).

Nos anos seguintes a Embrafilme continuou a se profissionalizar, aperfeiçoando sua abordagem mercadológica através de estudos geodemográficos e criando campanhas de marketing mais elaboradas para garantir o sucesso dos filmes que financiava (ou co-produzia) e distribuía.

No entanto, "Havia uma dupla política no interior da empresa. De um lado, o setor industrial e toda sua complexidade; de outro, o setor cultural com as diferentes demandas que as distintas atividades exigem." (GATTI, 2007a) Esse cenário era resultado da absorção de muitas funções por parte da estatal e acabou por torná-la lenta e onerosa e, embora os produtores cinematográficos pudessem, pela primeira vez na história, encontrar uma empresa confiável para lançar seus filmes no mercado (GATTI, 2007a; MARSON, 2006), a Embrafilme se tornou grande demais para se sustentar "com a necessidade de instalar controles de contabilidade, de produtividade de capital, de identificar quanto era repassado ao produtor, quanto era investido dentro dela mesma etc” (GATTI, 2007a).

Além disso, "o investimento maciço que estava sendo feito em produção não encontrava equivalente em comercialização[...] Não havia uma política de mercado, havia uma política de produção, independente de uma política de mercado [...]" (ALTBERG, 1983, p. 65-76 apud GATTI, 2007a) e os conflitos com distribuidores independentes, distribuidores internacionais, exibidores e grupos de cineastas levaram a Embrafilme a tomar decisões difíceis e, por fim, chegou a uma situação de caos administrativo (e depois, com a crise econômica, contábil) (GATTI, 2007a). Em 1987 a Embrafilme passou por uma nova reestruturação, separando suas atividades de produção e financiamento das de distribuição, contudo, mesmo que sua diretoria tenha elaborado planos para evitar seu fechamento, acabou sendo extinta pelo governo de Fernando Collor de Mello em 1990. (GATTI, 2007a; MinC, 2008; BRASIL, 1990a; BRASIL, 1990b; BRASIL, 1990c; MARSON, 2006)

Entre 1990 e 1991, o secretário de cultura (não havia ministro da cultura no período) Ipojuca Pontes foi incumbido de "enxugar" os elos que ligavam o Estado aos negócios do cinema, deixando um setor ainda despreparado sem proteção para competir com o produto estrangeiro. Houve a revogação de Leis protecionistas da indústria cinematográfica, a redução da exibição obrigatória de filmes brasileiros e também o fechamento de órgãos reguladores (Concine, Embrafilme e FCB) (GATTI, 2007a; MARSON, 2006). André Piero Gatti (2005) e Marcelo Ikeda (2010), consideram que as medidas e leis adotadas no período 1990-1993 foram devastadoras para o cinema brasileiro. Notavelmente, a edição da lei 8495/92(BRASIL, 1992) tornou o financiamento da produção cinematográfica bastante restrito, quase ao ponto de se questionar se seria esse um ponto de ruptura permanente entre o Estado e o cinema brasileiro. Com as privatizações e reestruturações dos órgãos culturais e autarquias relacionadas ao cinema ocorridas nos Governos Fernando Collor de Mello e Itamar Franco (inclusive dissolução do ministério da cultura, reduzido a uma secretaria), o cinema brasileiro perdeu suas agências financiadoras, grande parte de sua capacidade de produção e distribuição, levando ao surgimento de um vácuo no mercado, rapidamente ocupado pelo filme estrangeiro (GATTI, 2007a; IKEDA, 2010; MARSON, 2006).

Todavia, em 1993, negociações com o governo levaram à edição da lei do audiovisual, resultando na lei 8685/93 e na criação de novas leis de incentivo fiscal. A lei do Audiovisual e a lei Rouanet 


\section{O CLUSTER CINEMATOGRÁfiCo de PAULÍNIA: UMA ANÁLISE DA INOVAÇÃo E dO EMPREENDEDORISMO DA INDÚSTRIA DO CINEMA EM PAULÍNIA-SP}

surgiram como mecanismos de financiamento da atividade e são elementos responsáveis pelo ciclo do cinema brasileiro conhecido como "retomada" (GATTI, 2005; MARSON, 2006).

A Lei Rouanet e a Lei do Audiovisual funcionam como mecanismos de incentivo à cultura e proteção de mercado baseados em renúncia fiscal, permitindo às empresas investirem parte do montante devido de imposto de renda em produções artísticas (no caso da Lei do Audiovisual, especificamente em produções videofonográficas) e também permitem às empresas estrangeiras uma redução da tributação sobre a remessa de lucros ao exterior, caso invistam em co-produções nacionais (ALVARENGA, 2010). Em 1998, no entanto, esse modelo enfrentou uma grande crise. Com a má situação econômica, decorrente da alta do dólar e do aumento do risco país com as crises do México e da Rússia, o ano seguinte prometia uma safra quase nula de filmes rodados, deflagrando a fragilidade do modelo e a prevalência do modelo de financiamento de produções cinematográficas dependente do Estado (THIAGO, Paulo apud MARSON, 2006; ALVARENGA, 2010).

Nesse período, seguiram-se disputas de interesse entre a classe artística, o governo, os distribuidores internacionais e os exibidores, resultando na criação de diversas normas jurídicas e adaptações às existentes, de forma a fortalecer a inserção do filme brasileiro em seu mercado e evitar que o filme estrangeiro ocupe todos os nichos (GATTI, 2005).

Uma observação do modelo de produção do período da retomada também fez perceber alguns vícios do modelo de financiamento vigente. André Gatti (2007b apud ALVARENGA, 2010) aponta 3 fatores problema: A falta de controle na apuração de projetos; A possibilidade de se financiar $100 \%$ da obra sem contrapartida da produtora; e a situação em que o risco de se investir na distribuição dos produtos finais levava produtores a obter seus ganhos no orçamento de produção, o que aumentava o custo total do filme.

Em 1999, foi instalada a Comissão de Cinema do Senado Federal para discutir essas questões e dar rumo à dimensão legislativa da política do cinema nacional. A discussão sobre os investimentos realizados pelo Estado brasileiro durante o período girou em torno das críticas que se fazia ao resultado efetivo que esses filmes obtinham. Notavelmente, muitos deles não se pagavam e não agregavam valor à cultura (GATTI, 2005; MASSON, 1999). Essa iniciativa de discussão Estadocinema evolui para uma comissão permanente no senado e, posteriormente, na criação da Agência Nacional de Cinema (ANCINE) em 2001 (GATTI, 2005; ANCINE, s/d) com o objetivo de "induzir condições isonômicas de competição nas relações dos agentes econômicos da atividade cinematográfica e videofonográfica no Brasil, proporcionando o desenvolvimento de uma indústria forte, competitiva e auto-sustentada" (ANCINE, s/d).

A ANCINE tem como competências: a execução da política nacional de fomento ao cinema (na forma do art. $3^{\circ}$ da MP 2228-1), promover a participação de obras brasileiras em festivais internacionais e o exercício de funções regulatórias (execução das decisões de política pública e aplicação de sanções enquanto delegada do Estado) (ANCINE, s/d b; ANCINE s/d c;). Além de regular o acesso a verbas públicas para execução de projetos de audiovisual, a ANCINE também fiscaliza o cumprimento da "cota de telas" (percentagem obrigatória de exibição de produções nacionais em salas brasileiras) e combate a pirataria. (ANCINE, s/d b).

De outro lado do espectro, outro modelo se propõe a disputar espaço no cinema brasileiro. Em 1998, com a estreia de "Simão, o fantasma trapalhão", a Globo Filmes se inseriu no mercado nacional e provocando grandes transformações. Adotando um modelo "blockbuster" a Globo filmes emplacou 9 dos 10 filmes mais rentáveis lançados nos 10 anos seguintes a sua inauguração (BUTCHER, ZACHARIAS, GOMES e ADAMS, 2008). A Globo dispunha já de capital e de meios de comunicação para divulgar suas produções e co-produções (além de levar em consideração um marketing para o "filme brasileiro" em si), mas essa não é sua única vantagem competitiva: em entrevista para a publicação "Filme B", o diretor da divisão de projetos Temáticos e diretor de 


\section{Gustavo Mota Uchoa e Reinaldo Dias}

operações da Globo Filmes Carlos Eduardo Rodrigues afirma que o acumulo de conhecimento acerca do mercado nacional (decorrente também de erros passados) e seu modelo de parcerias (tanto no âmbito artístico como intervenções no roteiro e no elenco quanto no âmbito econômico decidindo o posicionamento do filme e seu lançamento) são fatores essenciais para o sucesso da Globo (BUTCHER, ZACHARIAS, GOMES e ADAMS, 2008). A Globo filmes realizou algumas coproduções no polo de Paulínia (PMP, 2009), mas seu modelo se aproxima mais de uma Vera Cruz, com a cadeia de produção concentrada dentro de uma única empresa ou em um grupo restrito de associados do que com o modelo que é objeto de nosso estudo.

Seu modelo sustentado por um "star system" nacional e forte apoio dos meios de comunicação do grupo praticamente monopolizou o acesso de filmes brasileiros às telas de cinema nos anos 2000 (ANTONELLI, 2011).

\section{Método}

Para a identificação de um Cluster foi utilizada uma metodologia qualitativa descritiva (já que há trabalhos sobre Clusters em grande quantidade) e exploratória (já que nenhum trabalho desse tipo foi realizado quanto ao polo cinematográfico). Inicialmente, o planejamento consistia em fazer um breve levantamento bibliográfico e consolidação de referencial teórico para depois partir para o campo e realizar entrevistas semi-estruturadas com figurantes de filmes, empreendedores (donos de produtoras, diretores e donos de estabelecimentos vertical ou horizontalmente alinhados à cadeia de valor) e com um representante do poder público, no entanto, os desdobramentos ocorridos durante a pesquisa, decorrentes das eleições municipais dificultaram o acesso a uma figura pública. Mesmo assim, a assessoria de imprensa e a secretaria de cultura do município de Paulínia se dispuseram a fornecer dados e contatos a respeito das empresas do ramo cinematográfico instaladas na cidade, dados estes que responderiam às questões que seriam formuladas na entrevista. Foi entrevistado o Prof. Dr. Maurício Reinaldo Gonçalves (cuja obra foi utilizada extensamente na realização deste trabalho) e assim obtida a opinião de um especialista em cinema, com vistas a obter mais informações para a pesquisa.

Já as entrevistas com os empreendedores e figurantes foram feitas por telefone e com a utilização de questionário semi-estruturado.

\section{O polo de cinema de Paulínia}

Paulínia é uma cidade da região metropolitana de campinas, localizada a cerca de $120 \mathrm{~km}$ da cidade de São Paulo. A cidade tem aproximadamente 83 mil habitantes (IBGE, s/d) e é conhecida por abrigar várias indústrias do setor petroquímico como Exxon, Shell e Petrobrás (a maior refinaria de petróleo da Petrobrás, a REPLAN, fica em Paulínia), responsáveis pela elevada renda do município (PACHECO, 2009)

Visando diversificar as atividades da cidade, para que não ficasse eternamente dependente de uma indústria ligada a recursos não renováveis, o governo de Paulínia começou a sancionar leis de incentivo fiscal, principalmente voltadas para o setor cultural, parte do projeto "Paulínia magia do cinema". Posteriormente, também foi instalada infraestrutura de estúdio, escola de teatro, um teatro para espetáculos e outros aparatos, descritos na próxima seção.

Do polo de Paulínia, surgiram produções como "Tropa de Elite", "Chico Xavier", "Nosso lar", "O doce veneno do escorpião", "Meu país", "As mães de Chico Xavier", "Corações sujos" e o recentemente indicado a Cannes "Trabalhar cansa" (IMDb, s/d). (PMP, 2009; PACHECO, 2009) e todo esse sucesso passou a atrair o restante da cadeia produtiva de cinema (serviços de maquiagem, escolas de atores, locadoras de equipamentos pra filmagem, distribuidores de película, etc) e mão de obra (não só atores, mas também dublês, cameramen, fotógrafos, maquiadores, etc) para a cidade e se tornar um dos principais centros de produção cinematográfica do país. (GONSALEZ, 2010; 


\section{O CLUSTER CINEMATOGRÁfiCo de PAULÍNIA: UMA ANÁLISE DA INOVAÇÃO E dO EMPREENDEDORISMO DA INDÚSTRIA DO CINEMA EM PAULÍNIA-SP}

\section{PACHECO, 2009)}

\section{Cluster no polo?}

Vantagens comparativas: A cidade de Paulínia se localiza num ponto vantajoso em termos de logística, já que está conectada a uma malha viária extensa e se situa a uma distância relativamente pequena da cidade de São Paulo. A cidade também dispõe de recursos financeiros, advindos das indústrias do setor petroquímico, que podem ser utilizados para financiar investimentos do porte de um polo cinematográfico (a cidade é responsável por $9 \%$ do PIB nacional). Por último, a proximidade de Campinas e São Paulo ainda contribuem para o acesso a mão de obra especializada.

Presença de indústrias correlatas e de apoio: de acordo com as informações fornecidas pela secretaria de cultura do município de Paulínia:

“o Polo Cinematográfico da cidade contempla:

- Escola Espaço Cultura

- Paulínia Film Commission

- Escritórios temporários

- Theatro Municipal de Paulínia

- 4 estúdios totalmente estruturados para abrigar filmagens

- 1 estúdio de animação em fase de finalização

- Festival Paulínia de Cinema

- Edital de Patrocínio"

Abriu-se um novo campo de atividades profissionais no Município, ligadas às artes, tais como: cenografia, fotografia, figurino, roteiro, montagem, visagismo, sonografia, etc. E que são necessárias para que se desenvolva a produção cinematográfica. Além disso, vários alunos da Escola Espaço Cultura trabalham profissionalmente em produções rodadas na cidade, ou seja, é presente um elemento crucial para o desenvolvimento da cadeia de valor, a instituição de ensino voltada para a atividade da região.

Condições de demanda: O polo de Paulínia atende, principalmente, uma demanda nacional, tendo produzido filmes de qualidade e que trouxeram retorno financeiro (um grande desafio na área) e de reconhecimento internacional. Em entrevista, o Prof. Dr. Maurício Reinaldo Gonçalves afirma que o cinema brasileiro é buscado, mas não encontrado pela população, ou seja, que há demanda reprimida por essas produções e que esse gargalo é provocado por uma questão socioeconômica, tanto do ponto de vista da precificação das salas de cinema quanto da acomodação do mercado à estética do produto estrangeiro massificado (não ligada à qualidade em si como já foi explicitado por Celso Masson em 1999) e também do estereotipo que a classe média construiu do cinema brasileiro em décadas passadas como de um filme de qualidade inferior.

Estratégia estrutura e rivalidade: As produções brasileiras competem pelo investimento, não pelo mercado. O que o referencial teórico, as entrevistas e os questionários nos revelaram a respeito da estrutura da produção cinematográfica no Brasil foi que ela sempre teve uma ligação forte com o Estado e que o grande gargalo do setor é o binômio financiamento (para a criação)-Exibição (fazer com que o filme brasileiro ocupe as telas). Normalmente as produções brasileiras ficam entravadas em um nicho do mercado (empurradas para lá pelo filme estrangeiro) e disputam essencialmente esse espaço, sendo que seu avanço quanto ao filme estrangeiro permanece instável, num ano sobe, no outro desce.

Desenvolvimento do Cluster: Através da análise dos dados fornecidos pela prefeitura e de entrevistas com empreendedores pudemos observar que o número de empresas do ramo cinematográfico e de 


\section{Gustavo Mota Uchoa e Reinaldo Dias}

correlatas aumentou desde a implantação do projeto. Os empreendedores vieram atraídos principalmente pelos incentivos e propostas infraestruturais, não havendo ainda aproveitamento ideal de serviços disponíveis ou cooperação entre as empresas centrais (produtoras e distribuidoras). A ligação entre essas empresas e as indústrias correlatas, a film commission e o festival de cinema da cidade são coordenados pelo setor público e os empreendedores do ramo ainda se relacionam de forma incipiente (ou, pelo menos, negligenciam o real potencial a ser aproveitado). As produções seguem ainda um modelo de um paradigma anterior, somente modificado pelas condições locais de estruturação produtiva (por exemplo, muitas produtoras que filmaram em Paulínia e seus associados ainda se mantiveram em outras cidades, como São Paulo).

\section{Cinema da nação, cinema da cidade?}

Durante a leitura do referencial teórico, esbarramos constantemente na questão do relacionamento entre a produção cinematográfica brasileira e o Estado, desde as iniciativas de utilização do cinema para a educação durante o Estado Novo de Vargas (RAMOS, 2004) até a criação de uma empresa estatal para cuidar da distribuição e do financiamento de filmes nacionais. A política do cinema sempre foi uma característica peculiar da nossa produção, ao analisarmos a história do cinema percebemos que em poucos momentos há uma produção cinematográfica verdadeiramente “independente". É claro que sempre há uma fonte financiadora, quer seja o próprio diretor, quer seja o empresário, quer seja o Estado. O que é notável é o espaço que ocupa o Estado brasileiro nessa equação, já que parece ser a fonte de investimento preferida pelos cineastas (ou, no mínimo, a mais procurada), percebe-se a dimensão dessa ligação quando, no governo Collor, o Estado retira seu apoio ao setor e o cinema brasileiro fica fragilizado ao ponto de temer por sua sobrevivência. Contudo, seria esse fardo passível de ser carregado por um governo municipal? Enquanto as esferas de influência na área de cultura e cinema no espectro nacional são relativamente estáveis, principalmente se considerando a permanência de pesquisadores, professores, cineastas e produtores importantes nos principais órgãos reguladores e publicações específicas, a esfera municipal está muito mais sujeita a oscilações em sua política cultural conforme se alternam as gestões e que também deve utilizar seus recursos em benefício da população local. Levando-se em conta os desdobramentos mais recentes, pode se perceber que uma simples mudança de mandato permite que o investimento instalado seja abandonado, o festival cancelado e o potencial de desenvolvimento do cinema em Paulínia pareça menos promissor. Também se faz ver a indiferença de grande parte dos agentes que outrora utilizaram os recursos disponibilizados pelo polo à sua degradação, desde que possam obter recursos por outros meios.

Na opinião de Maurício Gonçalves, o cinema é uma questão a ser abordada por todas as esferas de governo e também pela sociedade civil, resta então saber qual a melhor maneira de se conciliar essas questões dentro do atual contexto econômico e cultural. Aponta-se também a questão da democratização do acesso aos meios culturais (não só do espectador ao lazer, mas também do produtor independente ou do crítico aos mecanismos de financiamento) para que haja heterogeneidade na produção, para que haja crítica e inovação e para que o "sabor" regional possa ter espaço onde o produto internacional ou o nacional fortemente impulsionado pelos meios de comunicação impõem seus produtos (complementado em ANTONELLI, 2011).

\section{Considerações finais}

O que foi observado através das entrevistas e também durante a procura pelo material a ser analisado forneceu informações vitais para se considerar que a estruturação produtiva do polo de Paulínia configura um Cluster incipiente. Trata-se de um conjunto de empresas que se deslocaram (ou deslocaram suas atividades para a região) visando obter facilidades de produções em torno de um aparato instalado pelo Estado (nesse caso, extraordinariamente, na esfera municipal) e que não sustentam o nível de suas atividades no local sem o contínuo apoio financeiro/estrutural dele provindo, o que condiz com a evolução histórica da produção cinematográfica brasileira da qual fala, 


\section{O CLUSTER CINEMATOGRÁfiCo de PAULÍNIA: UMA ANÁLISE DA INOVAÇÃo E dO EMPREENDEDORISMO DA INDÚSTRIA DO CINEMA EM PAULÍNIA-SP}

principalmente, Jean-Claude Bernardet (2009 apud ALVARENGA, 2010). Essas empresas, embora possam se valer de algumas externalidades positivas decorrentes de sua concentração, tais como gerar demanda agregada por atores e serviços, ainda não se relacionam intensamente e só são, até certo ponto, unidos porque seus interesses são essencialmente os mesmos (financiamento do Estado, uso de instalações etc.), ou seja, convergem, mas não cooperam. Há, no entanto, potencial para que surja esse relacionamento, desde que os grilhões do velho paradigma sejam rompidos por empreendedores inovadores e que a oportunidade de atender um polo cinematográfico como um conjunto de clientes seja enxergada e devidamente explorada por outros agentes do setor privado, criando mais escolas de atores e cineastas (movimento que já cresce no Brasil, como nos informa Maurício Gonçalves), criando oficinas de cenografia e de costura de figurinos no local (ainda se traz muito esse tipo de confecção de São Paulo ou de onde quer que já estivesse estabelecida sua produção) e criando serviços para atender conjuntamente os produtores da região em termos de assessoria de imprensa, distribuição e marketing (sendo que esse espaço é pouco coberto pelo setor público, ainda que fosse mais interessante que o encargo coubesse ao setor privado).

Nota-se que a indústria cinematográfica ainda não é competitiva como um todo em termos financeiros fora do "modelo Globo" (mesmo que o seja em termos estético-artísticos), considera-se que a produção de filmes é quase impossível sem o apoio do Estado ou desvinculada a poderosos mecanismos de formação de opinião e divulgação próprios. Poucos filmes dão retorno financeiro, já que a exibição e distribuição configuram um estreito gargalo.

Por último, ressalta-se a importância do Estado como meio de democratização do acesso a meios de produção e exibição de obras cinematográficas, cuja heterogeneidade enriquece nossa cultura.

\section{Referências}

ALTBERG, J.A. Política cultural no cinema, Rio de janeiro: IUPERJ/FUNARTE, 1983.

ALVARENGA, Marcos Vinícius T. Cineastas e a formação da ANCINE (1999-2003). São Carlos: UFSCar, 2010. [Dissertação (Mestrado) -- Universidade Federal de São Carlos, 2010.

AMORIM, M. A. “Clusters" como estratégia de desenvolvimento industrial no Ceará. Fortaleza: Banco do Nordeste, 1998.

ANCINE - Agência Nacional de Cinema. Apresentação. s/d Disponível em http://www.ancine.gov.br/ancine/apresentacao Acesso 15 set 2013.

Regulação - o que é. s/d b Disponível em < http://www.ancine.gov.br/regulacao/o-que-e >

Acesso 16 set 2013.

Competências da ANCINE. s/d c Disponível em http://www.ancine.gov.br/competencias-daancine Acesso 16 set 2013.

ANTONELLI, Juliana Sangion. Vale a pena ver de novo? A Globo filmes e as novas configurações do audiovisual brasileiro na pós-retomada. Campinas: Instituto de Artes - Unicamp, 2011 [Tese de Doutorado].

ARAÚJO, Luciana C. O Cinema Silencioso pernambucano e suas histórias. Mnemocine. 2008.

Disponível em:

$<$ http://www.mnemocine.art.br/index.php?option=com_content\&view=article\&id=85:0-cinema-

silencioso-pernambucano-e-suas-historias\&catid=42:historia-no-cinema-historia-docinema\&Itemid=67>. Acesso 11 jun. 2012.

ASSAF, Alice Gonzaga. 50 anos de Cinédia. Rio de Janeiro: Record, 1987.

BARROSO, Henrique César Muzzio de Paiva; BATISTA, Paulo César de Sousa. Estratégias das Pequenas e Médias Empresas (PME's) na formação do Cluster têxtil da Região Metropolitana de 
Fortaleza $(R M F)$ In: EGEPE - ENCONTRO DE ESTUDOS SOBRE EMPREENDEDORISMO E GESTÃO DE PEQUENAS EMPRESAS. 3. 2003, Brasília. Anais... Brasília: UEM/UEL/UnB, 2003, p. 650-665.

BERNARDET, Jean-Claude. Cinema brasileiro: propostas para uma história. Rio de Janeiro: Paz e Terra, 1979.

Cinema brasileiro: propostas para uma história. $2^{\mathrm{A}}$ ed. Rio de Janeiro: Companhia das Letras, 2009.

BRASIL. Decreto-lei $n^{\circ}$ 862, de 12 de setembro de 1969. Autoriza a criação da Emprêsa Brasileira de Filmes Sociedade Anônima (EMBRAFILME), e dá outras providências. Poder Executivo, Brasília, DF, 27 set. 1969.

- Decreto no 99.226, de 27 de abril de 1990. Dispõe sobre a dissolução de entidades da Administração Pública Federal, e dá outras providências. Poder Executivo, Brasília, DF, 27 abr. 1990b.

- Medida provisória $\mathrm{n}^{0} 151$, de 15 de março de 1990. Dispõe sobre a organização da Presidencia da Republica e dos Ministerios, e dá outras providências. Poder Executivo, Brasília, DF, 15 mar. 1990a.

- Lei no 8.029, de 12 de abril de 1990. Dispõe sobre a extinção e dissolução de entidades da administração Pública Federal, e dá outras providências. Poder Executivo, Brasília, DF, 15 mar. 1990c.

Lei $n^{0} 8405$, de 9 de janeiro de 1992. Autoriza o Poder Executivo a instituir como fundação pública a Coordenação de Aperfeiçoamento de Pessoal de Nível Superior -

CAPES e dá outras providências. Poder Executivo, Brasília, DF, 09 jan. 1992

BUTCHER, Pedro; ZACHARIAS, João Cândido; GOMES, Alice; ADAMS, Barbara. Globo Filmes. Filme B. edição especial. mai. 2008.

CINÉDIA. História. s/d. disponível em <http://www.cinedia.com.br/cinedia.html> Acesso em 20 jan. 2012.

CASSIOLATO, José Eduardo; LASTRES, Helena M. M. O foco em arranjos produtivos e inovativos locais de micro e pequenas empresas. In: CASSIOLATO, J.E.; LASTRES, H. M. M.; MACIEL, M. L. (orgs). Pequena empresa: cooperação e desenvolvimento local. Rio de Janeiro: Relume Dumará Editora, 2003. p. 21-34.

CATANI, Afrânio M. História do cinema brasileiro: 4 ensaios. São Paulo: Panorama, 2004

COUTINHO, Gisela Aguiar Soares. Reestruturação da cadeia produtiva têxtil em Valença-RJ. Revista Economia \& Gestão v.8 n.17, pp.01-21 2008.

FABRIS, Mariarosaria. Nelson Pereira dos Santos: um olhar neo-realista?. São Paulo: Edusp, 1994.

FERREIRA, Suzana Cristina de Souza. Adhemar Gonzaga e a Cinédia : Imagens de um país que dança. Belo Horizonte: Faculdade de Filosofia e Ciências Humanas - UFMG, 2006 [Tese de Doutorado]

GATTI, André P. Embrafilme e o cinema brasileiro [recurso eletrônico] São Paulo: Centro Cultural São Paulo, 2007a. 113 p. em PDF - (cadernos de pesquisa; v. 6)

Distribuição e exibição na indústria cinematográfica brasileira (1993 - 2003). Campinas: Instituto de Artes - Unicamp, 2005 [Tese de Doutorado]

O mercado cinematográfica brasileiro: uma situação global? In: MELEIRO, A. (org.). Cinema no mundo: indústria, política e mercado. América Latina Volume II. São Paulo: Escrituras Ed., 2007b p. 120. 


\section{O CLUSTER CINEMATOGRÁfiCo de PAULÍNIA: UMA ANÁLISE DA INOVAÇÃO E dO EMPREENDEDORISMO DA INDÚSTRIA DO CINEMA EM PAULÍNIA-SP}

GOMES, Paulo Emílio S. Cinema: trajetória no subdesenvolvimento. Rio de Janeiro: Paz e Terra, 1980.

GONÇALVES, Reinaldo; BAUMANN, Renato; CANUTO, Otaviano; PRADO, Luiz Carlos D.A Nova Economia Internacional: Uma Perspectiva Brasileira. Rio de Janeiro: Campus, 1998

GONSALEZ, Alexandra. Luz, câmera, empregos. Revista Você S/A. n. 148, São Paulo. p. 62-65. Out. 2010.

IKEDA, Marcelo. Distribuição de longas-metragens brasileiros a partir das leis de incentivo (19952007): um panorama. in: X Estudos de Cinema e Audiovisual. p. 89-150. SOCINE. São Paulo, 2010.

IMDb - THE INTERNET MOVIE DATABASE. S/D. Disponível em: 〈http://www.imdb.com/>. Acesso em 04 jul. 2012.

INSTITUTO BRASILEIRO DE GEOGRAFIA E ESTATÍSTICA - IBGE. Dados básicos, S/D. Disponível em: <HTTP://www.ibge.gov.br/cidadesat/painel/painel.php?codmun=353650>. Acesso em: 22 abr. 2012.

LIMA, André Luís M. A Chanchada brasileira e a mídia: O diálogo com o rádio, a imprensa, a televisão e o cinema nos anos 50. São Paulo: Escola de Comunicação e Artes - USP, 2007

[Dissertação de Mestrado]

LYRA, Bernadette. A emergência de gêneros no cinema brasileiro: do primeiro cinema às chanchadas e pornochanchadas. Conexão - Comunicação e cultura. Vol.6 nº 11,pp.141-159, 2007.

LOBATO, Ana Lúcia. Os Ciclos Regionais de Minas Gerais, Norte e Nordeste (1912-1930) in:

RAMOS, Fernão (org.) História do cinema brasileiro. São Paulo: Art,1987, pp. 65-95

MARTINELLI, S. (org.) Vera Cruz : Imagens e História do Cinema Brasileiro. São Paulo: ABooks, 2002.

MARSON, Melina I. O Cinema da Retomada: Estado e cinema no Brasil da dissolução da Embrafilme à criação da ANCINE. Campinas: Instituto de Filosofia e Ciências Humanas - Unicamp, 2006 [Dissertação de Mestrado]

MASSON, Celso. Caros, ruins e você paga. Veja. n.1604 p.114, jun. 1999.

MENDONÇA, Leandro José Luz Riodades de. Cinema e indústria: o conceito de modo de produção cinematográfico e o cinema brasileiro. Tese de doutorado. ECA-USP, 2007.

MinC - Ministério da cultura. Cinemateca. Disponível em <http://www.cinemateca.gov.br/cgibin/wxis.exe/iah/?IsisScript=iah/iah.xis\&base=FILMOGRA FIA\&lang=p\&nextAction=lnk\&exprSearch=ID=000202\&format=detailed.pft $\# 1, \mathrm{~s} / \mathrm{d}>$ Acesso em 20 abr. 2012.

Centro técnico Audiovisual. A Embrafilme. Disponível em

<http://www.ctav.gov.br/2008/10/10/a-embrafilme/>, 2008. Acesso 01 jul. 2012.

ORTIZ, Renato. A moderna tradição brasileira. São Paulo: Brasiliense, 2001.

PACHECO, Camila Caprini de Campos. Paulínia: Investimento público em cinema como propulsor cultural, social e econômico. São Paulo: CEACC/ECA-USP, 2009. [Trabalho de conclusão de curso]

PORTER, Michael E. THE competitive advantage of nations. Harvard Business Review, Boston, p.71-91. mar-abr. 1990a.

A vantagem competitiva das nações. Tradução de Valtensir Dutra. 14a ed. Rio de Janeiro: 
Campus, 1990b.

Cluster and the new economics of competition. Harvard Business Review, Boston, p.77-90. nov-dez, 1998.

PREFEITURA MUNICIPAL DE PAULÍNIA - PMP. Cultura presta contas: Primeira audiência pública do Fundo Municpal de Cultura, 2009. Disponível em:

<http://www.culturapaulinia.com.br/arquivos/audiencias/audiencia.pdf>. Acesso em: 20 mai. 2012.

QUEIROZ, Eliana. A scena muda como fonte para a história do cinema brasileiro (1921-1933). São Paulo: Escola de Comunicação e Artes - USP, 1981. [Dissertação de Mestrado]

RAMOS, Fernão. Mauro documentarista. Revista USP. v.63 p.157-168 São Paulo, 2004.

RAMOS, Fernão; MIRANDA, Luiz Felipe. Enciclopédia do cinema brasileiro. São Paulo: Senac, 2000.

SABEL, Charles F.; Piore, Michael J. The second industrial divide: possibilities for prosperity. New York: Basic Books, 1984.

SALLES, Filipe. A Atlântida de 1950 a 1960. s/d Disponível em <http://www.mnemocine.com.br/cinema/historiatextos/atlantfil.htm>. Acesso em 14 dez. 2011

SEBRAE. Subsídios para a identificação de clusters no Brasil: atividades da indústria (relatório de pesquisa). São Paulo: SEBRAE, 2002.

Arranjo Produtivo Local. Brasília: SEBRAE, 2010.

SIMIS, Anita. Estado e Cinema no Brasil. São Paulo: Annablume, 1996.

SONZOGNO, Victor Enrico Clusters industriais: um estudo sobre o cluster de calçados de Franca e seu real grau de internacionalização. São Paulo: FEA-USP, 2003 [Trabalho de conclusão de curso].

VIEIRA, João Luiz. A Chanchada e o Cinema Carioca (1930-1955) in: RAMOS, Fernão (Org.)

História do cinema brasileiro. São Paulo: Art,1987, pp.131-187. 